\title{
Iranian public hospitals' challenges regarding revenue deficits: A mixed- method study
}

\author{
Ali Sarabi-Asiabar ${ }^{1}$, Saeide Alidoost ${ }^{1}$, Rahim Sohrabi ${ }^{2}$, Roghayeh Mohammadibakhsh $^{1}$, Aziz Rezapour ${ }^{1}$, \\ Zahra Moazamigoudarzi ${ }^{3}$, Narges Rafiei*1 (D)
}

Received: 30 Sep 2019

Published: 21 Sep 2020

\section{Abstract}

Background: The main part of hospitals' funding comes from insurance organizations. In some cases, for different reasons such as not filed services or unpaid health insurance bills, a part of these funding cannot be derived from health insurance companies. This study aims to describe different aspects of the hospitals' revenue deficits in Iranian public hospitals.

Methods: This was a mixed-method study consisting of qualitative and quantitative studies. Qualitative data were collected through 17 semi-structured interviews and were analyzed using the analytical framework by MAXQDA.10. Quantitative data were analyzed by the TOPSIS method and Smart TOPSIS Solver.3.2.0.

Results: Based on the framework analysis, five sets of the underlying causes of hospital revenue deficits were identified and categorized in 5 themes: bottlenecks, direct causes of revenue deficits, root causes of revenue deficits, revenue deficits management strategies, and challenges and barriers to managing revenue deficits. Through inadequate clinical documentation and failed to provide the insurance organization's requirements, the surgical units, operating rooms, and inpatient units were found as the main sources of revenue deficit. Lack of senior management commitment and inconsistency of insurance organizations for evaluating claims are often listed as the major barriers to effective implementation of corrective interventions.

Conclusion: Revenue deficits occurs in most hospital departments and in all stages of converting services into revenue, and a variety of human and organizational factors contribute to them. Therefore, focusing on the main causes of deductions and the participation of all individuals and departments involved in it is critical to reducing deductions.

Keywords: Hospital, Revenue deficit, Deductions, Insurance organizations

Conflicts of Interest: None declared

Funding: Iran University of Medical Sciences

*This work has been published under CC BY-NC-SA 1.0 license.

Copyright $\odot$ Iran University of Medical Sciences

Cite this article as: Sarabi-Asiabar A, Alidoost S, Sohrabi R, Mohammadibakhsh R, Rezapour A, Moazamigoudarzi Z, Rafiei N. Iranian public hospitals' challenges regarding revenue deficits: A mixed-method study. Med J Islam Repub Iran. 2020 (21 Sep);34:124. https://doi.org/10.47176/mjiri.34.124

\section{Introduction}

The health care system in Iran has been funded by the

Corresponding author: Narges Rafiei, rafiei.n@iums.ac.ir

1. Health Management and Economics Research Center, Iran University of Medical Sciences, Tehran, Iran

2. Iranian Social Security Organization, Zanjan Province Health Administration, Zanjan, Iran

3. Health Management and Social Development Research Center, Golestan University of Medical Sciences, Gorgan, Iran contribution of private and public sectors through different

\section{$\uparrow$ What is "already known” in this topic:}

There are a number of studies on revenue deficits in Iranian hospitals, most of which examine revenue deficits amounts and compare them across different hospitals and insurance organizations.

\section{$\rightarrow$ What this article adds:}

Bottlenecks, direct causes of revenue deficits, root causes of revenue deficits, revenue deficits management strategies, and challenges and barriers to managing revenue deficits were identified as possible themes for hospital revenue deficits. The analysis showed the importance of improving the interaction between the Ministry of Health and insurance organizations in Iran, and the role of hospital manager as key factors, and also lack of sufficient motivation, knowledge of providers and poor regulatory systems as root causes of revenue deficits. 
financing agents who are responsible for managing the budget. The Iran Health Insurance Organization (IHIO), the Iranian Social Security Organization (ISSO), and the Armed Forces Medical Services Insurance Organization (AFMSIO) are the largest healthcare financier in the public sector, respectively. The beneficiaries of them are civil servants, self-employed, rural populations, and others. Private health insurance organizations that are independently responsible for providing supplemental insurance plans, and non-governmental organizations (NGOs) such as nonprofit institutions serving households (NPISH) are part of the private sector $(1,2)$.

More than $40 \%$ of the health expenditures have been allocated to inpatients and out-patients services. The Ministry of Health and Medical Education (MoHME) with the collaboration of Universities of Medical Sciences, is the main provider of inpatient services. According to Iran NHA Report, the MoHME owns $70 \%$ of total hospitals which are public properties $(1,3)$. These hospitals have different funding sources; annual budget from the government, the payment of fee-for-service and perdiem by insurance organizations and MoHME (to road traffic accident victims). In addition, based on the services that patients receive, they have to pay amounts (co-payment) which are collected as special income of the hospitals (35).

In a reform method implemented in the payment mechanism by MoHME (1995) which is known as hospital autonomy reform (Khod-Gardani), public hospitals were allowed to fund themselves and covering their current costs through revenue-generating fees (fee-for services) $(6,7)$. Given that operating expenditures account for a large share of total hospital costs (over 90\%), special income has recently received increasing attention among senior hospital administrators. Hospitals are required to review the productivity of provided services and the contributed factors in the loss of resources due to the reduced budget support and the reliance on their own revenues (810).

Insurance organizations play a major role in generating special revenues for hospitals and include the Iran Health Insurance Organization, Iranian Social Security Organization, Military Personnel Insurance Organization, other non-governmental organizations (NGOs), oil companies, Khomeini Relief Foundation, and the Ministry of Defense (3). According to the National Health Accounts in 2015, social security funds (Health Insurance Organization and Social Security Organization) and complementary insurance organizations covered approximately $50 \%$ of hospital costs (1). Hence, revenues from the provision of services play an important financing role and, if managed properly, are reliable sources for hospitals. However, sometimes a part of the revenues loses its present value due to various reasons such as non-payment by insurance organizations and delayed payment, with hospitals incurring considerable costs (11-13). Failure to receive a part of the revenues from hospital services is referred to as "hospital deductions of revenue" and indicates the difference between the costs that are reimbursed (by patients and insurance organizations) and the amount that should have been reim- bursed based on official fees.

There are a number of studies on the deductions of revenue in Iranian hospitals, most of which examine deduction amounts and compare them across different hospitals and insurance organizations (14-17). Some studies have investigated the factors that directly correlate with deductions and have identified poor documentation and noncompliance with the requirements of insurance organizations as the most important factors $(15,16,18,19)$. A number of studies have proposed strategies for reducing deductions of revenue, including personnel training and increased interaction with representatives of insurance organizations $(15,20)$. However, hospital deductions and their different aspects have not been thoroughly examined, especially from the perspective of process owners. There is only one such study in the area of primary health care in Iran, where the results showed a significant difference between deductions in Iranian health centers and hospital deductions $(21,22)$. Thus, the purpose of the present study is to examine different aspects of hospital deductions of revenue and provide strategies for reducing them.

\section{Methods}

The study was a mixed-method study consisting of qualitative and quantitative studies that had been conducted from June to December 2017 in Tehran.

\section{Qualitative Research}

Data were collected by semi-structured interviews aimed to assess the awareness and knowledge of finance experts in hospitals. A finance expert was defined by more than five years of work experience as a financier at the hospital and having health or finance-related education. All the participants were selected using a purposeful sampling strategy (maximum diversity sampling). Samples were collected from all the super-specialty, multi-specialty and general public hospitals and at all levels related to hospital income (such as revenue experts, revenue officers, finance chiefs and hospital administrators). They got the information sheet and invitation via email and further scheduling was done by phone. The average length of interviews was 45 minutes which were recorded by Dictaphone. The interviews continued until saturation was reached, at which point no new subject or strategy was presented by the interviewees. Finally, 17 people who were financial experts at public hospitals in Tehran were interviewed (Table 1).

The Analytical Framework Method (Gale et al. 2013) was used for data analysis. It includes seven stages: 1) Transcription, 2) Familiarization with the interview, 3) Coding, 4) Developing a working analytical framework, 5) Applying the analytical framework, 6) Charting data into the framework matrix, and 7) Interpreting the data (23). Accordingly, the records were carefully transcribed and compared to the notes taken during the interviews (Stages 1 and 2). Mixed-Method (Deductive and Inductive) was used for coding data, whereby the first three interviews, considering the interviewers' agreement, were independently coded by two interviewers. Increasing the credibility, coded interviews were sent to the interviewees 


\begin{tabular}{|c|c|c|c|c|c|}
\hline ID & Age & Sex & $\begin{array}{c}\text { Work Experience } \\
\text { (Year) }\end{array}$ & Job Title & Education \\
\hline$\overline{1}$ & 48 & $\bar{F}$ & 24 & Chief Financial Officer & High school Diploma \\
\hline 2 & 48 & $\mathrm{~F}$ & 19 & Healthcare Financial Director & High school Diploma \\
\hline 3 & 38 & M & 7 & Healthcare Financial Director & A.S. in Accounting \\
\hline 4 & 29 & $\mathrm{~F}$ & 7 & $\begin{array}{c}\text { Assistant Chief Financial Officer- Hospital } \\
\text { Revenue Manager }\end{array}$ & B.Sc. in Accounting \\
\hline 5 & 26 & $\mathrm{~F}$ & 5 & Hospital Revenue Manager & B.Sc. in Accounting \\
\hline 6 & 36 & $\mathrm{~F}$ & 11 & Healthcare Revenue Specialist & B.Sc. in Accounting \\
\hline 7 & 29 & $\mathrm{~F}$ & 11 & Healthcare Revenue Specialist & B.Sc. in Computer Science \\
\hline 8 & 48 & M & 23 & Chief Financial Officer & M.Sc. in Accounting \\
\hline 9 & 48 & M & 22 & Hospital Revenue Manager & A.S. in Accounting \\
\hline 10 & 38 & $\mathrm{~F}$ & 10 & $\begin{array}{c}\text { Director of Health Economy and Information } \\
\text { Management, } \\
\text { Chair of the Audit Committee }\end{array}$ & M.Sc. in Public Administration \\
\hline 11 & 30 & $\mathrm{~F}$ & 7 & Hospital Revenue Manager & B.Sc. in Accounting \\
\hline 12 & 33 & M & 9 & Healthcare Financial Director & B.Sc. in Accounting \\
\hline 13 & 37 & M & 12 & Healthcare Financial Director & B.Sc. in Accounting \\
\hline 14 & 35 & $\mathrm{~F}$ & 10 & Healthcare Revenue Specialist & B.Sc. in Accounting \\
\hline 15 & 47 & $\mathrm{~F}$ & 20 & Hospital Revenue Manager & B.Sc. in Accounting \\
\hline 16 & 42 & M & 12 & Hospital CEO & M.Sc. in Health Services Management \\
\hline 17 & 39 & M & 18 & Hospital Revenue Manager & B.Sc. in Accounting \\
\hline
\end{tabular}

to be verified. Also, codes were extracted from the other papers, and then a preliminary list of codes was prepared based on the initial interviews and literature review. A preliminary list of codes has been provided (Stage 3 ). The identified codes were categorized, initial themes were formed, and an analytic framework was prepared based on them (Stage 4). The grouping codes and themes were used for coding the rest of the interviews. During this process, the analytical framework was changed if necessary (Stage 5). Finally, the framework matrix was developed (Stage 6). MAXQDA.10 was used for data analysis. Ethical considerations included asking permission from participants to record audio, ensuring them about the confidentiality of the information, and allowing them to leave the study at any time. Ethical approval for this study was obtained from the Ethics Committee of the Iran University of Medical Sciences Research with the ethics code No. IR.IUMS.REC 1395.28646.

For assessing the quality of the current qualitative study, we ensured four trustworthiness criteria suggested by Lincoln and Guba including credibility, transferability, dependability and, conformability. Credibility was achieved through long-term interaction and ongoing observation by the researcher and also revising the interviews by the interviewees. All the research members participated in the coding and text analysis to increase the dependability, and also they endorsed the results, which enhanced the conformability. Text-based and clear descriptions have boosted the transferability of qualitative findings (24).

\section{Quantitative Research}

The cross-sectional study was carried out to prioritize solutions to reduce hospital revenue deficits. The strategies were ranked according to a researcher- madequestionnaire and TOPSIS method. The Technique for Order of Preference by Similarity to Ideal Solution (TOPSIS) is a Multi-Criteria Decision Analysis Method (MCDM), which was developed by Hwang and Yoon in 1981. TOPSIS is a procedure to find the best alternative among a set of feasible alternatives regarding their geo- metric distance from the Positive Ideal Solution (PIS) and the Negative Ideal Solution (NIS). This technique is based upon the concept that the chosen alternative should have the shortest distance from the PIS and the longest distance from the NIS. TOPSIS logic is rational (0-1). The final ranking is obtained by means of the closeness index. The closest alternative to 1 is the ideal solution, and the closest alternative to 0 is the less ideal solution (anti-ideal solution) (25). A tool was designed to rank and prioritize the decisions. This questionnaire consists of eight items (strategies) covering three criteria of effectiveness, acceptability, and low-cost which were completed by ten financial experts in the hospital revenue area. The items were rated using a 10-point Likert scale. Smart TOPSIS Solver 3.2.0 was used for data analysis. The criteria were weighted using the entropy method: 0.1613 for cost, 0.3351 for effectiveness, and 0.5037 for acceptability. The questionnaire's validity verified by seven health services managers.

\section{Results}

Most of the participants were hospital finance managers, with a bachelor's degree or higher in accounting. On average, they had 13 years of work experiment and at least 5 years of involvement with departments of revenue and finance in public hospitals.

Five themes were identified based on the framework analyzing, including Bottlenecks (6 sub-themes), Direct Causes of Revenue Deficits (4 sub-themes), Root Causes of Revenue Deficits (5 sub-themes), Revenue Deficits Management Strategies (8 sub-themes), and Challenges and Barriers to Manage Revenue Deficits (5 sub-themes). The results of the framework analysis are provided in Table 2.

\section{Bottlenecks}

Based on the data analysis, there are six major bottlenecks that are actually the main sources of revenue deficits and their importance is depending on the number and amount of deductions, which include: Outpatient departments, Surgical Units and operating rooms (surgery and 
Table 2. Identified themes and subthemes based on framework analysis

\begin{tabular}{|c|c|}
\hline Theme & Subtheme \\
\hline Bottlenecks & $\begin{array}{l}\text { - Outpatient departments } \\
\text { - Surgical Units, operating rooms (surgery and anesthesia) } \\
\text { - Hospital hotel services } \\
\text { - Inpatient consultation by specialists } \\
\text { - Inpatient documents } \\
\text { - Paraclinical departments such as radiology and laboratory }\end{array}$ \\
\hline Direct causes of revenue deficits & $\begin{array}{l}\text { - Poor clinical documentation } \\
\text { - Failure to submit complete, timely and accurate financial documentation } \\
\text { - Inconsistencies in documents and reports } \\
\text { - Not complying with the regulatory requirements of the insurer organizations }\end{array}$ \\
\hline Root causes of revenue deficits & $\begin{array}{l}\text { - Infrastructure challenges and issues } \\
\text { - Poor regulatory systems } \\
\text {-Limited awareness and knowledge of healthcare providers about financial cutbacks and insurer regulations } \\
\text { - Insufficient interaction between hospitals and insurance organizations } \\
\text { - Service providers' lack of incentive to control deductions (Moral Hazard) }\end{array}$ \\
\hline $\begin{array}{l}\text { Revenue deficits Management } \\
\text { Strategies }\end{array}$ & $\begin{array}{l}\text { - Analysis, assessment and feedback on revenue deficits } \\
\text { - Organization of human resources } \\
\text { - Coordinating and empowering the service employees } \\
\text { - Interaction with insurance organizations } \\
\text { - Strengthening regulatory systems } \\
\text { - Motivate workforce } \\
\text { - Good planning } \\
\text { - Creating an organizational structure }\end{array}$ \\
\hline $\begin{array}{l}\text { Challenges and barriers to reducing } \\
\text { revenue deficits }\end{array}$ & $\begin{array}{l}\text { - The clinicians' refusal and senior managers' reluctant for involving } \\
\text { - Outsourced units deductions at the hospital } \\
\text { - Lack of coordination among representatives of insurance organizations } \\
\text { - Based on the staffs' idea, the non-logical relationship between the deductible amount and the refunded amount } \\
\text { - The insufficient collaboration of Vice- Chancellor in Treatment Affairs }\end{array}$ \\
\hline
\end{tabular}

anesthesia), Hospital hotel services, Inpatient consultation by specialists, Inpatient documents, and para-clinical departments such as radiology and laboratory.

Most of the participants highlighted the role of surgical units and operating rooms, especially surgeons and anesthesiologists, as the most important source of revenue deficits. One interviewee commented that:

"...In this scenario, the most important unit is surgical units and operating rooms, where the surgery and anesthesia codes are recorded. Any non-compliance with the insurance company instructions, e.g. any extra request, is considered a deduction. Since these services are very expensive, so deduction in one service can be a very large sum of money." (Interview 9)

The other source which has a considerable quota in this issue is the specialists' consultation for inpatient. This is due to various factors such as the redundant request for consultation, bringing up more than three issues in a consultation session, and consultation of a general practitioner with a specialist. A participant explained:

"...The specialists' consultation for inpatient, notably Phone Consultation, has a significant role in deductions. Giving consultation without a formal request or through an undocumented phone consultation is not acceptable by insurance companies. While the doctor or department manager is responsible for completing these documents." (Interview 1)

The risk of losing a part of inpatient revenue as income deduction is very high, and it can happen through various levels of a care process. Preparing adequate documents in this unit as one of the most important bottlenecks can sig- nificantly reduce the portion of deductions. This issue has been confirmed by most of the interviewees:

“...Inpatient units provide a variety of care services, including clinical and para-clinical. Thus, they can impose many deductions via not following the regulations of insurance organizations or incomplete documentation." (Interview 3)

\section{Direct Causes of Revenue Deficits}

Conforming to the qualitative framework analysis, the direct causes of hospital revenue deficits were included: poor clinical documentation, failure to submit complete, timely and accurate financial documentation, inconsistencies in documents and reports, and not complying with the regulatory requirements of the insurer organizations.

Recording the services which are excluded from the commitment of the insurance organizations; requesting higher prices (Up-coding), resulting from non-compliance between the requested tariff and the insurance liability price range; e.g. some additional costs in global surgeries such as ambulance transportation cost in appendix surgery or the cost of hospital-acquired complications are examples of not complying with the regulatory requirements of the insurer organizations. The finance director of one hospital argued that:

"...Requesting additional services or submitting surgery codes which are not covered by insurance at all can cause a lot of deductions that are quite expensive in the operating room." (Interview 13)

Incompetent documentation and delay in submitting evidence are considered as the major causes of deduction in 
all hospital departments. Financial experts believe that failure to send timely documentation from hospital departments to discharge and income sector, as well as from the hospital to insurer organizations, could lead to significant deductions, one interviewee commented that:

"...Timely submission of documents affects deductions, reviewing, and doctors' fees. In terms of review, I will have more time to review the evidence deeply; can survey the medical documents in addition to invoices. Therefore, the doctor's fee would be calculated precisely and properly." (Interview 10)

\section{Root Causes of Revenue Deficits}

Actually, root causes are underlying factors of the above-mentioned matters and the most important elements for controlling revenue deficits and includes: Infrastructure challenges and issues, Poor regulatory system, Limited awareness and knowledge of healthcare providers about financial cutbacks and insurer regulations, Insufficient interaction between hospitals and insurance organizations, and Service providers' lack of incentive to control deductions.

Most of the financial experts in this study agree that the poverty of information and knowledge of healthcare providers regarding financial cutbacks and insurer regulations is more important than the rest of the factors and need to be considered specifically in the design and implementation of the intervention. Healthcare providers at different levels, from physicians and nurses to the secretaries of departments and various units' staff, such as the discharge and income sectors are faced with this issue. Separating the underlying factors is impossible because they are all interconnected as parts of a cycle. The revenue deficits don't have any serious effect on the services providers' income; as a result, they don't have enough motivation to control these deductions, which leads to their lack of effort to become familiar with insurance regulations and so on. This faulty loop would make problems in the process of reducing the deductions.

The importance of sufficient interactions between hospitals and insurance organizations is not more or less than the mentioned factors. Without the participation of insurance organizations, hospitals usually face many problems in controlling deductions. Delays in the submission of circulars by the insurer and the enforcement of their laws, as well as the disagreement between the hospital and insurer regarding the no coverage services, are some of the inconsistencies which are the results of this issue. One interviewee pointed to the importance of this issue:

“... Interaction with insurance organizations is very important; a settled insurance representative in the hospitals can help to prevent deduction issues. We can take feedback from them and modify the documentation based on their professional comments. Unfortunately, the corporation of some insurance companies is very poor, and without sufficient interaction, the revenue deficits will not be resolved." (Interview 4)

Inefficiencies in different resources such as human resources, physical, and data resources in hospitals are some examples of infrastructure issues. The absence of commitment by the senior hospital managers can lose out all the other staff's efforts to control revenue deductions. One interviewee stated the following regarding the role of the senior managers:

"The hospital's CEO and the top managers have a very important role in deductions, and they can be very influential in addressing the issues that we bring up about physicians and staff. But unfortunately, they often don't pay attention to them or side with the physicians." (Interview 13)

The poor regulatory system can increase the risk of incurring deficits in each sector of the healthcare revenue cycle (the process to track the revenue from patients, from their initial appointment or encounter with the health care system to their final payment of the balance). The precise monitoring of all stages of this process from service delivery to documenting and submitting records, can dramatically reduce hospital revenue deficits. One interviewee hinted at this issue by stating that:

"...Supervision is crucial. Many deductions incur when physicians and staff are not supervised, and there isn't any control over the work of secretaries and the hospital discharge unit. Unfortunately, there is no feedback after reporting the staff's mistakes to the managers." (Interview 12)

\section{Strategies for Reducing Revenue Deficits}

In consequence, analyzing the participants' comments and literature review, eight strategies were identified. The strategies were ranked based on three criteria: Effectiveness, Acceptability, and Low-Cost. The ranking indicated: Interaction with insurance organizations; Analysis, assessment and feedback on revenue deficit; and Coordinating and empowering the service employees are respectively the three top-priority strategies for reducing revenue deduction. The ranking's conclusions are provided in Table 3.

The first preferred method is Interaction with insurance organizations. This policy refers to create a team-oriented atmosphere among the hospital managers and insurance organization's agents. This relationship can help the

Table 3. Ranking the strategies for reducing hospital deductions from revenue

\begin{tabular}{llc}
\hline Alternatives & CL & Rank \\
\hline Interaction with insurance organizations & 0.8685 & 1 \\
Analysis, assessment and feedback on revenue deficits & 0.8526 & 2 \\
Coordination and empowerment of human resources & 0.8386 & 3 \\
Motivate workforce & 0.4574 & 4 \\
Good planning & 0.3125 & 5 \\
Organization of human resources & 0.3063 & 6 \\
Creating an organizational structure & 0.2749 & 7 \\
Strengthening regulatory systems & 0.2374 & 8 \\
\hline
\end{tabular}


healthcare managers and providers to reach the potential of insurance experts to strengthen their systems and train their staff in order to meet the demands of the other party. The majority of the participants highlighted the effect of interaction with insurance organizations, especially through their representatives at the hospital:

"...In order to achieve the goal, hospital finance administrators must have regular meetings with insurance experts, not only with executives, to discuss all the conflicts, and cooperate to find the proper solutions. Thus, problems would quickly be solved or minimized." (Interview 3)

Analysis, assessment, and feedback on revenue deficits is the second alternative, which suggests the standardized, structured, and periodic appraisal of the hospital's financial statements that followed by specialized interpreting per relevant authorities, which lead to sharing the feedback with involved departments and staff. Evaluating the initial status of deductions can be the first step towards reducing them, which can promote to design appropriate interventions. Moreover, regular reviewing can lay the groundwork for the continuous improvement of the hospitals' deduction control process. One expert from a hospital that had successfully controlled its deductions of revenue stated that:

"... In order to reduce the deductions of secretaries, we got the hospital's discharge and revenue units involved, and they provided feedback to each other. That is, if discharge staffs make mistakes, revenue experts correct them and vice versa. So they control each other." (Interview 8)

The third strategy is the coordination and empowerment of human resources, which involves the increased commitment of the hospital's senior managers, internal coordination, and enhancement of the knowledge and skills of the finance team. Senior management's attention to the issue of the revenue deficit and their obligation to control this dilemma is a major step to overcome this problem. Developing the human resources' capacity and enhancing their information about the importance of budgeting as well as deduction-related regulations and requirements is an effective element. One interviewee considered empowerment along with motivation and incentives as the key to reducing hospital deductions from revenue:

"...For this purpose, all the crews, including secretaries, physicians, surgeons, and the hospital discharge and revenue teams, must have enough information about deductions, their financial consequences, and their contribution impact. They must receive basic and continuous training in this area and keep updated about the slightest changes in deduction-related processes and regulations." (Interview 11)

Motivating the workforce is another critical scenario that addresses what will happen when revenue deficit is decreased. The staff must find out how their struggle to achieve this goal might impact their income. Envisioning these possible reductions and connecting them to their earning motivated them even when the end goal was only distantly conceivable. The gratifications could be as simple as getting a positive reaction when discussing their work or receiving an acknowledgment or they could be as significant as getting additional bonus or benefits. The interviewees often mentioned how wonderful it would be.

Albeit other strategies such as Good planning (modifying the revenue deficit control process and scheming to checkup and timely submission of documents), Organization of human resources (selecting of qualified individuals and engaging them in appropriate positions), Creating an organizational structure (establishing a Revenue Deficits Reduction Committee in the hospital), and Strengthening regulatory channels (Supervising involved personnel in the entire health finance system) are ranked lower in the arrangement, but choosing the best policy for all hospitals is depends on their conditions, facilities, and priorities.

\section{Discussion}

In this mixed-method study, Iranian public hospitals' challenges regarding their revenue deficits were evaluated from different aspects and several solutions were offered. The overall conclusion from this study declared that the revenue deficit issue is a communal subject and all the diagnostic and therapeutic departments and even managing and financing sectors are faced with that. Given the wide range of services in inpatient units and the operating room, they are more assisted in emerging this dilemma. Previous studies have backed up this claim and shown that the highest amounts of deductions occur in the inpatient units especially the operating rooms $(15,26-28)$. In addition, pharmacies have more underlying factors than paraclinical departments. This comment has been supported by some articles $(26,29)$. However, other publications have reported conflicting results regarding the highest and lowest share of departments in this issue. This contradictory can be the result of the difference in the type of hospitals (i.e., public vs. private hospitals, or teaching vs. nonteaching, etc.), the variety of the assessed insurance organizations and also not considering the revenues and only focusing on the deductions of departments (i.e., without taking into account the share of deductions from the revenues of each department). The main obstacles to controlling revenue deficit in public hospitals in comparison to private hospitals are the irresponsibility of senior managers and lack of motivation for employees. Also using students and temporary employees in clinical and administrative sectors, especially in the hospital revenue unit, is the Achilles' heel of the teaching hospitals (30-32).

The study's findings showed that direct causes and root causes are the effective themes in this regard. The first theme breaks down into poor clinical documentation; failure to submit complete, timely and accurate financial statements; inconsistencies in documents and reports; and not complying with the regulatory requirements of the insurer organizations. Most of the participants agree that the role of initial subcategories' is very intense, and this point is consistent with the results of other studies $(13,33$, 34). Omrani et al. in 2011 have investigated the incidence and causes of income deductions in hospitals affiliated with Shahid Beheshti University of Medical Sciences. They have focused on revenue deficit due to insurance claims and non-registered services. Inadequate documentation and failed to submit the Insurance Organization's requirement are the most important causes of revenue def- 
icit. The poor health information system and inappropriate training of human resources specifically in financing units, are samples of basic issues that impact the process of services' recording and lead to losing a part of hospital income. As non-registered services annually impose more than 60 million Rials losses on hospitals' income (34). In most studies, poor documentation, and not adhering with insurers' regulations have been referred to as critical factors in revenue deficit $(15,21,30,35,36)$.

Root causes are contributing to the provision of basic conditions at all stages in revenue deficit, containing Infrastructure challenges and issues, Poor regulatory systems, Limited awareness and knowledge of healthcare providers about financial cutbacks and insurer regulations, Insufficient interaction between hospitals and insurance organizations, and Service providers' lack of incentive to control deductions (Moral Hazard). The results of different studies are consistent with the present findings $(28,30$, $34,35)$. Nasirirad et al. (2010) have bolded the importance of the interaction between hospitals and insurance organizations and explained that not adhering to the insurer's documentation requirements, delayed reimbursement by insurer organizations and inconsistency between insurance organizations can make financial challenges for hospitals (30).

Lack of knowledge of healthcare providers about financial cutbacks and insurer legislation has been evaluated by scientists. Moalemi et al. have tried to figure out the effective elements in the Social Security Organization hospital's income loss. They have discovered that weak domination of related employees on medical records, insufficient education on how hospitals collaborate with insurance representatives and insurance regulations especially on documentation, and inadequate education about diagnostic services' tariffs are critical points in this issue (28). Knowledge fault of income unit employees about health records and insurance principles have also been cited by another study (30).

Catching the health finance system drawbacks without granting scientific and sensible solutions is destroying time and funds. Eight advocated strategies consist of Interaction with insurance organizations, Analysis, assessment and feedback on revenue deficit, Coordination and empowerment of human resources, Motivate workforce, Good planning, Organization of human resources, Creating an organizational structure, and Strengthening regulatory systems which are listed respectively according to the ranking system. This list has been defended by other papers' results $(17,30,33,34,36)$. Nasirirad et al. were conducted a qualitative study and reported some significant approaches to reduce revenue deficits such as training and encouraging all the financial staff like secretaries, finance unit clerks, physicians, and nurses, also, establishing good co-operation between insurance agents and involved crews to share the relevant information which is completely consistent with the results of the present study (30). Bagheri et al. study recommended three interventions: instituting a revenue tracking board, acquainting staff with documentation principles, and interaction with insurance organizations (17). Due to the effect of all hospital staff performance, whether the therapeutic or the support team, in the rate of revenue and losses, so all contingency and preventive measures should be taken with the participation of all members. The secretaries of departments, as pioneering representatives who have a direct relationship with medical records and financial documents, have a significant role in providing and submitting records to the insurance organization and consequently improving the revenue deductions.

Mokhtari et al. have emphasized that serving correct and principled instruction and training for Hospital Information System (HIS) users, also increasing their cognition of revenue cuts and the impact of proper registration of services can dramatically reduce the risk of deductions (33). Also, in other studies, the effectiveness of educational interventions for reducing deductions was underlined (37-40) but the implementation of educational interventions is a dilemma for teaching hospitals. Temporary and short-term students and interns participation makes continuous and comprehensive training challenging since due to turnover, training must be repeated for new staff and hospitals often miss out on continuing education (30).

Given that failure to submit complete, timely, and accurate financial documentation is one of the most important factors and often occurs due to staff neglect of the submission due dates, the positive impact of HIS on solving this problem is undeniable $(34,41)$. Park et al. showed that using HIS led to increasing both inpatient and outpatient services' revenues (42). Therefore, a steady revision of documentary evidence and training of health care providers, especially physicians regarding how to properly copy and complete the medical records, can improve documentation and significantly safeguard the revenues of healthcare organizations.

The other strategy is a quantitative and qualitative analysis of deductions, which underlines the role of medical records experts in evaluating and analyzing deductions. Educating this group can produce good results in improving the hospital revenue cycle $(15,29,43)$.

Since the revenue deficit is only the impediment to healthcare organizations and physicians and staff do not suffer from this issue, so they do not feel obliged to participate in compensating for losses, as a result, there is no incentive to prevent this trouble. So healthcare organizations will be faced with a considerable amount of deductions and, consequently, lack of financial resources. Therefore, by adjusting the salary of physicians and staff with the amount of deduction, they can be motivated to modify the hospital revenue cycle. This point has been emphasized and confirmed by the study's participants and previous studies as a high-priority strategy $(30,34,35)$.

As with the majority of studies, this research is subject to some limitations. Not allowing one of the interviewees to record the interview was one of them that was overcome by taking field notes by the interviewer. The restriction of access was the other one that made this study available only in public hospitals in Tehran.

\section{Conclusion}

All the diagnostic and therapeutic departments, espe- 
cially inpatient and surgery units, are faced with revenue deficits due to inappropriate and incomplete documentation and failed to provide the insurance organization's requirements. Missing of senior management commitment, the unfamiliarity of different providers of the various aspects of revenue deficits and their lack of incentives to control deductions play a significant role in this subject. Interaction with insurance organizations, coordination and empowerment of human resources, and analysis and assessment of revenue deficits and feedback to individuals and departments involved, can play a significant role in bridling revenue deficits and increasing hospital revenues.

\section{Acknowledgment}

This study has been funded and supported by Iran University of Medical Sciences (IUMS); Grant No. 95-02163-28646.

\section{Conflict of Interests}

The authors declare that they have no competing interests.

\section{References}

1. National health accounts, Islamic Republic of Iran. World Health Organization, 2015.

2. Zakeri M, Olyaeemanesh A, Zanganeh M, Kazemian M, Rashidian A, Abouhalaj M, et al. The financing of the health system in the Islamic Republic of Iran: A National Health Account (NHA) approach. Med J Islam Repub Iran. 2015;29:243.

3. Hajizadeh M, Nghiem HS. Hospital care in Iran: an examination of national health system performance. Int $\mathrm{J}$ Healthcare Manag. 2013;6(3):201-10.

4. Lankarani KB, Alavian SM, Peymani P. Health in the Islamic Republic of Iran, challenges and progresses. Med J Islam Repub Iran. 2013;27(1):42-9.

5. Health system profile, Islamic Republic of Iran. Regional Health Systems Observatory, World Health Organization, 2006.

6. Ravaghi H, Foroughi Z, Nemati A, Be'lorgeot VD. A holistic view on implementing hospital autonomy reforms in developing countries: a systematic review. Health Policy Plan. 2018; 33(18):1118-27.

7. Doshmangir L, Rashidian A, Jafari M, Ravaghi H, Takian A. Fail to prepare and you can prepare to fail: the experience of financing path changes in teaching hospitals in Iran. BMC Health Serv Res. 2016;16:138.

8. Kleweno C, O'Toole R, Ballreich J, Pollak A. Does fracture care make money for the hospital? An analysis of hospital revenues and costs for treatment of common fractures. J Orthop Trauma. 2015;29(7):219-24

9. Jafari M, Rashidian A, Abolhasani F, Mohammad K, Yazdani S, Parkerton P, et al. Space or no space for managing public hospitals; a qualitative study of hospital autonomy in Iran. Int $\mathrm{J}$ Health Plan Manag. 2011;26(3):e121-e37.

10. Nabilou B, Yusefzadeh H, Rezapour A, Ebadi Fard Azar F, Salem Safi P, Sarabi Asiabar A, et al. The productivity and its barriers in public hospitals: case study of Iran. Med J Islam Repub Iran. 2016;30:316

11. Akortsu M, Abor P. Financing public healthcare institutions in Ghana. J Health Organ Manag. 2011;25(2):128 -41.

12. Ejughemre U. Accelerated reforms in healthcare financing: the need to scale up private sector participation in Nigeria. Int J Health Policy Manag. 2014;2(1):13-9.

13. Safarani S, Ravaghi H, Raeissi P, Maleki M. Financial challenges of teaching hospitals and providing solutions. J Educ Health Promot. 2018;7:155

14. Karimi S, Vesal S, Saeedfar S, Rezayatmand M. The study deductions of insurance bills and presenting suggestions approaches in Seyed Alshohada hospital. Health Inform Manag. 2011;7(Special Issue):594-600.
15. Mohammadi A, Azizi AA, Cheraghbaigi R, Mohammadi R, Zarei J, Valinejadi A. Analyzing the deductions applied by the Medical Services and Social Security Organization Insurance toward receivable bills by university hospitals of Khorramabad, Iran. Health Inform Manag. 2013;10(2):172-80.

16. Safdari R, Sharifian R, Ghazi Saeedi M, Masoori N, Azad Manjir ZS. The amount and causes deductions of bills in Tehran University of Medical Sciences hospitals. Payavard Salamat. 2011;5(2):61-70.

17. Bagheri H, Amiri M. Investigating the causes of deductions from insurers' organizations from patient records in one of the Iranian hospitals. J Health Manage. 2012;4(3,4):17-24.

18. Mosadeghrad A, Arab M, Afshari M. The impact of Quality Management on reducing bill deductions at operating theatre department of Valiasr Hospital: A participatory Action Research. Hospital. 2017;16(1):93-101.

19. Khorrmmy F, Eshpala RH, Baniasadi T, Azarmehr N, Mohammady F. Prioritizing insurance deductions factors of Shahid Mohammadi hospital inpatients records using Shannon Entropy, Bandar Abbas, Iran. Hormozgan Med J. 2013;17(1):77-82.

20. Safdari R, Karami M, Moini M. Causes of deductions made by the Social Security Insurance in hospital affiliated to Kashan University of Medical Sciences, Iran. Health Inform Manag. 2012;9(1):140-4.

21. Tabrizi JS, Alidoost S, Mashhadi Abdolahi H. A qualitative study of bottlenecks and causes of fractions for dedicated incomes of health centers and solutions for their reduction. Glob J Health Sci. 2016;8(9):58-65.

22. Tabrizi J, Alidoost S, Mardi A, Farshi-Khorsand M, Rahmat M. Assessing the causes of dedicated revenues' fractions in health care centers and strategies to reduce them (A qualitative study). Hospital. 2016;15(3):53-62.

23. Gale NK, Heath G, Cameron E, Rashid S, Redwood S. Using the framework method for the analysis of qualitative data in multidisciplinary health research. BMC Med Res Methodol. 2013;13(1):117.

24. Polit DF, Beck CT. Essentials of nursing research: appraising evidence for nursing practice. 8th ed: Lippincott; 2014.

25. Tzeng G-H, Huang J-J. Multiple attribute decision making: methods and applications. 1st ed. New York: Chapman and Hall/CRC; 2011.

26. Askary R, Dehghan HR, Bahrami MA, Keshmiri F. A survey in causes and rates of under reimbursement bills imposed on admitted patient's under social security insurance in medical teaching hospitals in Yazd province in 2008. Hospital. 2011;9(3,4):23-8.

27. Rezvanjou H, Sokhanvar M, Doshmangir L. Exploring the rate and causes of deductions imposed on Social Security and Health Insurance's bills related to inpatients in two hospitals affiliated with Tabriz University of Medical Sciences. Depict Health. 2017;7(4):7-13.

28. Moalemi S, Shamsabadi A, Meshkani Z, Alikiani A, Kazemi Karyani A. Survey and comparison on the causes of deduction in admitted Social Insurance: Bahonar and Arjmand hospital in Kerman. Assoc Health Inform Manage Iran. 2014;8(1):17-23.

29. Tavakoli N, Saghaeyannejad S, Rezayatmand M, Moshaveri F, Ghaderi I. Deductions applied by Khadamat-e Darman Insurance Company on patients' bills at teaching hospitals affiliated to Isfahan University of Medical Sciences. Health Inform Manag. 2006;3(2):5361.

30. Nasirirad N, Rashidian A, Joodaki H, Akbari Haghighi F, Arab M. Assessing issues and problems in relationship between basic insurance organizations and university hospitals: a qualitative research. Hospital. 2010;9(1,2):5-18.

31. Ravangard R, Keshtkaran V, Niknam SH, Yusefi A, Heidari A. The decision-making styles of managers of public and private hospitals in Shiraz. Hospital. 2013;12(3):39-45.

32. Alidoost S, Rezapour A, Sohrabi S, Mohammadibakhsh R, SarabiAsiabar A, Rafiei N. Causes of revenue deficits of university hospitals and strategies to reduce them. Hospital. 2019;18(1):67-78.

33. Mokhtari S, Eskandari S, Ayazi Z. Operators' performance evaluation on the hospital information system about the deductions of educational and medical Hajar hospital in 2012. J Shahrekord Uni Med Sci. 2014;15(6):86-91.

34. Omrani D, Farajzadeh F, Rashidi G. Rate and causes of income deductions in hospitals affiliated with Shahid Beheshti University of Medical Science in 2011. J Med Council Islami Repub Iran. 2012;30(3):265-71.

35. Norooz Sarvestani E, Pour Mohammadi K, Kavoosi Z, Yousefi AR. 
The amount and causes insurance deductions of Shohada-e Sarvestan hospital and ways to reduce it by using the techniques of problemsolving, 2012. J Manage Med Inform Sci. 2015;2(2):122-32.

36. Safdari R, Ghazi Saeedi M, Sheykhotayefe M, Jebraeily M, Seyed Farajolah SS, Maserat E, et al. The study of insurance deductions from point of insurance professionl in educational hospitals of Mashhad University of Medical Sciences. Payavard Salamat. 2017;11(1):10-9.

37. Khalesi N, Gohari MR, Vatankhah S, Abbasimani Z. The effect of employee training on the amount of insurance fractions at Firoozgar teaching hospital: 2008-2009. J Health Administration. 2011;14(43):19-26

38. Oldfield M. Case study: changing behaviours to improve documentation and optimize hospital revenue. Nurs Leadersh (Tor Ont). 2007;20(1):40-8.

39. Mosadeghrad AM, Afshari M, Nasrolahi R, Daneshgar S, Corani Bahador R. The impact of education on reducing bill deductions in a hospital: A case study. Hakim Health Sys Res. 2017;20(3):156-63.

40. Tavakoli N, Jahanbakhsh M, Akbari M, Baktashian M, Hasanzadeh A, Sadeghpour S. The study of inpatient medical records on hospital deductions: An interventional study. J Educ Health Prom. 2015;4:38.

41. Blair K, Dunn E. Maximizing patient care revenue throughout a major HIS conversion: teamwork and planning help organizations keep patient care revenue flowing during implementation of a new health information system. Healthcare Fin Manag. 2015:84-9.

42. Park W-S, Yi SY, Kim S-A, Song J-S, Kwak YH. Association between the implementation of a laboratory information system and the revenue of a general hospital. Arch Pathol Lab Med. 2005;129(6):766-71.

43. Mousazadeh Y, Soleymanzadeh M, Nosratnejad S. Exploring the rate and causes of inpatient records deductions covered by Iran Health Insurance: The case of a public hospital in Tabriz. Depict Health. 2017;8(2):119-25. 